\title{
Genome-wide analysis of the WRKY gene family in drumstick (Moringa oleifera Lam.)
}

\author{
Junjie Zhang Equal frst author, 1, 2, 3, 4 , Endian Yang ${ }^{\text {Equal first author, } 4 \text {, Qian He }}{ }^{3,4}$, Mengfei Lin ${ }^{1,2,3,4}$, Wei Zhou ${ }^{1,2,3,4}$, Ruiqi Pian ${ }^{1,2,3,4}$ \\ , Xiaoyang Chen ${ }^{\text {Corresp. 1, 2, 3, } 4}$ \\ ${ }^{1}$ State Key Laboratory for Conservation and Utilization of Subtropical Agro-bioresources (South China Agricultural University), Guangzhou, China \\ 2 Guangdong Key Laboratory for Innovative Development and Utilization of Forest Plant Germplasm, Guangzhou, China \\ 3 Guangdong Province Research Center of Woody Forage Engineering Technology, Guangzhou, China \\ ${ }^{4}$ College of Forestry and Landscape Architecture, South China Agricultural University, Guangzhou, China \\ Corresponding Author: Xiaoyang Chen \\ Email address: xychen@scau.edu.cn
}

WRKY proteins belong to one of the largest families of transcription factors. They have important functions in plant growth and development, signal transduction and stress responses. However, little information is available regarding the WRKY family in drumstick (Moringa oleifera Lam.). In the present study, we identified 54 MoWRKY genes in this species using genomic data. On the basis of structural features of the proteins they encode, the MoWRKY genes were classified into three main groups, with the second group being further divided into five subgroups. Phylogenetic trees constructed from the sequences of WRKY domains and overall amino acid compositions derived from drumstick and Arabidopsis were similar; the results indicated that the WRKY domain was the main evolutionary unit of WRKY genes. Gene structure and conserved motif analysis showed that genes with similar structures and proteins with similar motif compositions were usually clustered in the same class. Selective pressure analysis indicated that although neutral evolution and positive selection have happened in several MoWRKY genes, most have evolved under strong purifying selection. Moreover, different subgroups had evolved at different rates. The levels of expression of MoWRKY genes in response to five different abiotic stresses (salt, heat, drought, $\mathrm{H}_{2} \mathrm{O}_{2}$, cold) were evaluated by reverse transcription polymerase chain reaction (RT-PCR) and quantitative RT-PCR (qRT-PCR), with the results indicating that these genes had different expression levels and that some may be involved in abiotic stress responses. Our results will provide a foundation for cloning genes with specific functions for use in further research and applications. 
$4{ }^{1}$ State Key Laboratory for Conservation and Utilization of Subtropical Agro-bioresources (South China Agricultural

5 University), Guangzhou, China

$6{ }^{2}$ Guangdong Key Laboratory for Innovative Development and Utilization of Forest Plant Germplasm, Guangzhou,

7 China

$8{ }^{3}$ Guangdong Province Research Center of Woody Forage Engineering Technology, Guangzhou, China

$9{ }^{4}$ College of Forestry and Landscape Architecture, South China Agricultural University, Guangzhou, China

10

11 *Correspondence:

12 Dr. Xiaoyang Chen

13 xychen@scau.edu.cn

14 †These authors have contributed equally to this work. 
Abstract

WRKY proteins belong to one of the largest families of transcription factors. They have important functions in plant growth and development, signal transduction and stress responses. However, little information is available regarding the WRKY family in drumstick (Moringa oleifera Lam.). In the present study, we identified 54 MoWRKY genes in this species using genomic data. On the basis of structural features of the proteins they encode, the MoWRKY genes were classified into three main groups, with the second group being further divided into five subgroups. Phylogenetic trees constructed from the sequences of WRKY domains and overall amino acid compositions derived from drumstick and Arabidopsis were similar; the results indicated that the WRKY domain was the main evolutionary unit of $W R K Y$ genes. Gene structure and conserved motif analysis showed that genes with similar structures and proteins with similar motif compositions were usually clustered in the same class. Selective pressure analysis indicated that although neutral evolution and positive selection have happened in several MoWRKY genes, most have evolved under strong purifying selection. Moreover, different subgroups had evolved at different rates. The levels of expression of MoWRKY genes in response to five different abiotic stresses (salt, heat, drought, $\mathrm{H}_{2} \mathrm{O}_{2}$, cold) were evaluated by reverse transcription polymerase chain reaction (RT-PCR) and quantitative RT-PCR (qRTPCR), with the results indicating that these genes had different expression levels and that some may be involved in abiotic stress responses. Our results will provide a foundation for cloning genes with specific functions for use in further research and applications. 


\section{Introduction} controlling various important biological processes (Smith and Matthews, 2016). Out of numerous families of TFs, the WRKY gene family, named after a conserved WRKY domain, is one of the largest, and it is known to be

61 involved in a range of plant processes from germination to senescence (Chen et al., 2012; Eulgem et al., 2000;

62 Pandey and Somssich, 2009; Ulker and Somssich, 2004). WRKY genes were first identified in plant species and so on (Li et al., 2016; Zhang and Wang et al., 2005). The WRKY domain contains about 60 amino acid residues, comprising a highly conserved short amino acid sequence, WRKYGQK, at the N-terminus and an adjacent $\mathrm{C}_{2} \mathrm{H}_{2}$ or 
76

77

significant roles in signaling and regulation of expression during various biotic and abiotic stresses. In banana, MaWRKY26 activated jasmonic acid biosynthesis and enhanced cold tolerance in the fruit (Ye et al., 2016). In wheat, TaWRKY49 and TaWRKY62 were shown to participate in the defense response against the fungal pathogen Puccinia striiformis f. sp tritici (Pst), TaWRKY49 was shown to be a negative regulator and TaWRKY62 a positive regulator of wheat's HTSP resistance to Pst (Wang et al., 2017). WRKY TFs have also been implicated in the modulation of plant development. In the poplar Populus trichocarpa, PtrWRKY19 may function as a negative regulator of pith secondary wall formation (Yang et al., 2016). In foxtail millet, map-based cloning, combined with high-throughput sequencing, revealed that LP1, which encodes a novel WRKY TF, regulates panicle development (Xiang et al., 2017). WRKY TFs have also been shown to regulate the production of several secondary metabolites such as phenolic compounds including lignin, flavanols and tannins. In Arabidopsis, AtWRKY23 regulates the production of flavanols in auxin inducible manner (Grunewald et al., 2008; 2013). In rice, OsWRKY76 activates cold stress tolerance but suppresses PR genes and production of phytoalexins like terpene and the phenylpropanoid sakuranetin (Yokotani et al., 2013). In Withania somnifera, WsWRKY1 binds to W-box sequences in promoters encoding squalene synthase and squalene epoxidase, indicating that it has a direct role in the regulation of the triterpenoid pathway (Singh et al., 2017). What's more, the WRKYs always work interaction with other proteins, such as PeWRKY83 could interact with PeVQ proteins in moso bamboo (Wu et al., 2017) and physical interaction of WRKY75 with DELLA repressors were also found in Arabidopsis thaliana (Zhang et al., 2018).

Moringa oleifera Lam., commonly known as drumstick, belongs to the monogeneric family Moringaceae (Ramachandran, 1980). This species is widely cultivated in tropical and sub-tropical areas and has a long history of traditional medicine and culinary uses (Anwar et al., 2007; Zhang et al., 2017). Drumstick is considered to be a fastgrowing tree species and also it's a drought tolerant plant that can be grown in diverse soils except those that are 
97 waterlogged; it may also become important for biofuel production and has been used in a variety of industrial applications (Popoola and Obembe, 2013; Shih et al., 2011). Studies on drumstick transcription factors have hitherto rarely been reported because of a lack of genomic data for this species. The publication of the drumstick genome draft database (Tian et al., 2015) provides resources with which to carry out bioinformatics-based identification and analysis of WRKY TFs. In the present study, we have used these genomic resources to identify members of the WRKY gene family in drumstick and correlated their expression with various stress responses. We carried out a detailed study of the drumstick WRKY gene family, including gene classification, phylogenetic analysis, determination of structural organization and conserved motif composition, and assessed the selective pressures that have acted on different members of this family.

\section{Material and methods}

\section{Sequence database searches}

The complete genome and proteome sequences and General Feature Format (GFF) file for Arabidopsis were downloaded from TAIR (http://www.arabidopsis.org). The annotated drumstick genome sequences were provided by Yunnan Agricultural University. A WRKY-domain Hidden Markov Model (HMM) Profile, which was downloaded from Pfam (http://pfam.xfam.org/), was used as a query with which to search all of the annotated proteins in the drumstick genome with an E value cut-off of 1E-5. The candidates selected using HMMER were examined to determine whether they had typical features of WRKY proteins by employing the Pfam database. Finally, the CD-HIT program and the Pfam database were used to eliminate duplicate and incomplete sequences. Non-overlapping WRKY protein sequences were used for further analysis.

\section{Multiple sequence alignment and phylogenetic analyses}

The conserved WRKY domains of MoWRKY genes obtained using manual inspection in the Pfam program were

Peer) reviewing PDF | (2018:09:31687:2:1:NEW 26 Apr 2019) 
118

119

120

121

122

123

124

125

126

127

128

129

130

131

132

133

134

135

136

137

138

aligned using ClustalX 1.83 software. Phylogenetic analysis including 7 representative domains from Arabidopsis

was carried out to obtain better classifications of the different clades by applying the Neighbor-Joining method with

1000 bootstrap replicates using MEGA 6 software.

\section{Gene structure and motif composition analysis}

Analysis of the exon-intron organization of MoWRKYs was performed by comparing the coding sequences of MoWRKYs with their corresponding genomic sequences using GSDS software (http://gsds.cbi.pku.edu.cn).

Conserved motifs in each WRKY protein were investigated using the Multiple Expectation Maximization for Motif Elucidation (MEME) online program: http://meme-suite.org/. The following parameters were employed in analysis:

maximum number of motifs 20; minimum motif width 6; maximum motif width 50 .

\section{Promoter cis-acting elements analysis of MoWRKYs}

The promoter sequences, $1.5 \mathrm{~kb}$ upstream of the translation start site, of the MoWRKY genes were obtained from drumstick genome. PlantCARE (Lescot et al., 2002) was used to analyse the MoWRKY gene promoters and identify their cis-acting elements.

\section{Tests for selective pressure}

The multiple sequence alignment of drumstick MoWRKY proteins was carried out using ClustalW with default parameters. Then the sequences were trimmed to reduce gap penality. DNAMAN was used to search for nucleotide sequences encoding additional WRKY proteins, with the aligned MoWRKY protein sequences as guides. The synonymous $\left(\mathrm{K}_{\mathrm{S}}\right)$ and nonsynonymous $\left(\mathrm{K}_{\mathrm{a}}\right)$ substitution rates were calculated with the YN00 program in PAML4.9 with default parameters (Yang et al., 2007).

\section{Expression analysis}

To investigate the patterns of expression of MoWRKY genes under normal and abiotic stress conditions, seedlings 
of drumstick were cultivated in potting soil at $25^{\circ} \mathrm{C}$ under 14 : $10 \mathrm{~h}$ light: dark conditions in a growth chamber for 20 days before treatment. For salt and oxidative stress treatments, seedlings were sprayed for $12 \mathrm{~h}$ with, respectively, $150 \mathrm{mM} \mathrm{NaCl}$ and $\mathrm{H}_{2} \mathrm{O}_{2}$ solution. Cold and heat stress were applied by transferring plants to a climate chamber at, respectively, $4^{\circ} \mathrm{C}$ and $42^{\circ} \mathrm{C}$ for $12 \mathrm{~h}$. Drought stress was induced by withholding water for 2 weeks. Each treatment consisted of three replicates. After stress treatments, total RNA was isolated from leaf, stem, stem tip and root tissues of each seedling using a Total RNA Kit (OMEGA, Guangzhou, China). Total RNA was reverse transcribed into cDNA using a PrimeScript RT Master Mix (Perfect) Real Time Kit (Takara, Dalian, China). Gene specific primers were designed using Primer 5.0 and the $R P L$ gene was used as a reference (Deng et al., 2016). Expression of all MoWRKY genes was examined by RT-PCR and products from each sample were analyzed using a $1 \%$ agarose gel. Among all MoWRKY genes, 9 genes belonging to different subgroups were selected for analysis of gene expression levels using qRT-PCR according to the method described in Wei et al. (2016) and $R P L$ was amplified as a reference gene (Deng et al., 2016). Relative expression levels were evaluated using the $2^{-\Delta \Delta C T}$. Three technical replicates were conducted for test and reference genes of each sample to obtain precise and reproducible results. Statistical analysis was carried out using SPSS 19.0 software (SPSS Inc., Chicago, IL, USA), Duncan's multiple range test was used to detect differences among means. A $p$-value $<0.05$ was considered significant.

\section{Results}

\section{Identification of WRKY family members in the drumstick genome}

To identify all the WRKY genes in the drumstick genome, we employed the HMM profile of the WRKY domain (PF03106) as a query to search against the drumstick genome database using HMMER 3.0 and BLAST. A total of 54 nonredundant genes (Table 1) were identified as WRKY genes and a unique name was assigned to each drumstick WRKY gene, consisting of two italic letters denoting the source organism and sequential numbers: MoWRKY1 to 
160

161

162

163

164

165

166

167

168

169

170

171

172

173

174

175

176

177

178

179

180

MoWRKY54. All the putative 54 WRKY genes were further analyzed to confirm the presence of the WRKY domain

and all of them were annotated with gene ontology (GO) terms (Supplementary file 1). Fifty-three MoWRKY genes

containing complete WRKY domains were identified; only one gene (MoWRKY50) lacked a complete domain. The

highly conserved domain WRKYGQK was present in 52 of the MoWRKY proteins, whereas the remaining one

(MoWRKY24) contained a WRKYGKK domain. The lengths of the MoWRKY proteins ranged from 106

(MoWRKY24) to 834 (MoWRKY3) amino acids; the average length was 391 amino acids.

\section{Phylogenetic relationship and classification of MoWRKY genes}

The most prominent structural feature of WRKY genes is a conserved WRKY domain; there is also a zinc-finger

motif. Among the 54 MoWRKY proteins identified, nine MoWRKY proteins contained two WRKY domains; since

one MoWRKY protein did not have a complete WRKY domain, a total of 62 WRKY domains were found in this

study. In each protein that contained two WRKY domains, we designated these domains by the WRKY name plus N

or $\mathrm{C}$ for the $\mathrm{N}$-terminal or $\mathrm{C}$-terminal domain respectively. In order to examine phylogenetic relationships and

classify all 62 MoWRKY domains, a phylogenetic tree based on conserved WRKY domains was constructed.

Representative WRKY domains from Arabidopsis were used in our analysis, and the candidate domains were

obtained from Diao (2016) and Li (2016). Fig. 1 shows a multiple sequence alignment of the 62 WRKY domains.

Three major groups were identified, as previously described in poplar (He et al., 2012), pepper (Diao et al., 2016)

and carrot (Li et al., 2016). Additionally, several subgroups were apparent on the basis of the phylogenetic analysis.

Group I contained 10 WRKY proteins, of which all contain two WRKY domains except for MoWRKY10. This

member might have lost the N-terminal WRKY domain during evolution, since its single WRKY domain showed

high similarity to MoWRKY1C, which is located in the C-terminal WRKY domain clade, suggesting a common

origin for these two domains. Group II had the largest numbers of WRKY proteins and was divided into five major

PeerJ reviewing PDF | (2018:09:31687:2:1:NEW 26 Apr 2019) 
181

subgroups: IIa, IIb, IIc, IId and IIe. Subgroup IIa (3 members) and IIb (8 members) were two subgroups in the same branch, while subgroup IId (5 members) and IIe (7 members) were derived from one clade. Subgroup IIc, with 14 members, was more similar to group I than to any other subgroups according to the phylogenetic analysis. Furthermore, 6 WRKY domains belonged to group III, which is widely considered to be the most advanced in terms of evolution and the most relevant to adaptability (Dou et al., 2016; Kalde et al., 2003; Huang et al., 2016). Comparing the two phylogenetic trees, constructed for MoWRKY domains and genes, similar groups and subgroups were identified, though the classifications of a few members were different (Fig. 1 and Fig. S1), indicating that the conserved WRKY domain is an important unit in WRKY proteins.

\section{Structure analysis of MoWRKY genes}

Intron/exon organization and numbers of introns are typical imprints of evolution within some gene families. In this study, we analysed the structure of MoWRKY genes to gain further insight into evolutionary events that had shaped them and found that all MoWRKY genes contain introns (Fig. 2 A). The number of introns varies among genes, with the minimum, one intron, identified in five MoWRKYs (MoWRKY50, MoWRKY44, MoWRKY51, MoWRKY19 and MoWRKY11) of subgroup IIc and the maximum, 10 introns, being present in MoWRKY22. Gene structure analysis revealed that genes with similar structures always clustered in the same class. For example, six members of group III all contained 3 exons and 2 introns. Similarly, 5 exons and 4 introns were present in MoWRKY2, MoWRKY3, MoWRKY4, MoWRKY5 and MoWRKY6, which belonged to group I. However, the other 5 MoWRKYs in group I exhibited different gene structures.

\section{Motif composition analysis of MoWRKY proteins}

The conserved motifs of WRKY proteins in drumstick were investigated using the MEME online software suite (http://meme-suite.org/) to better understand the similarity and diversity of motif compositions. Twenty distinct 
202

203

204

205

206

207

208

209

210

211

212

213

214

215

216

217

218

219

220

221

222

motifs were identified and a schematic overview of these motifs is provided in Fig. 3. For MoWRKY proteins, motif

1 was broadly distributed in all MoWRKY proteins, which was corresponded to WRKY domain. Motif 3 was only

detected in the type I group. Motifs 5, 6, 7, 8, 9, 16, 17, 18 and 20 were only detected in the type II group; among

them, motifs 5 and 6 were only detected in subgroup IIa and IIb, motifs 8 and 9 were only detected in subgroup IIb,

motif 17 was only detected in subgroup IIc, and motif 16 was only detected in subgroup IId. Motifs 12 and 15 were

only detected in the type III group. Generally, proteins with similar motif compositions were clustered in the same

class indicating that members of the same class may have similar functions.

\section{Rapid expansion of group III WRKY genes in land plants}

Group III WRKY genes have only been characterized in flowering plants, and a large number of duplications and diversifications in this group appear to have resulted from different selection challenges (Dou et al., 2016; Huang et al., 2016; Kalde et al., 2003). To explore the evolutionary relationships of group III WRKY genes across drumstick and other land plant species, we performed a multiple sequence alignment among the 81 group III WRKY proteins from drumstick and another 7 species. A phylogenetic tree was constructed from the results of the alignment using the neighbor-joining method (Fig. 4). The marked difference in group III WRKY gene size among different species suggests that group III WRKY gene expansion occurred after the divergence of monocotyledons and dicotyledons. MoWRKY clearly shared more sequence similarity with VvWRKY and PaWRKY than with other WRKYs.

\section{The cis-acting elements analysis of MoWRKYs}

For further understand the possible functions of MoWRKY genes, the cis-acting elements in all MoWRKY genes promoters were analyzed using PlantCARE software based the drumstick genome data. Various types of cis-acting elements were found and all MoWRKY genes contained several cis-acting elements in their promoter regions. The 10 most common elements were summarized in Table 2. These elements included three hormone responsive elements 
223 (ABRE, CGTCA motif and TGACG motif), an essential element for the anaerobic inductio (ARE), a drought stress

224

225

226

227

228

229

230

231

232

233

234

235

236

237

238

239

240

241

242

243 responsive element (MBS), a heat stress responsive element (HSE) and four light responsive elements (Sp1, Box 4, G box and GT1 motif).

\section{Divergence in selective pressure between subgroups}

The ratio $(\omega)$ of the non-synonymous substitution rate $(K a)$ to the synonymous substitution rate $\left(K_{\mathrm{S}}\right)$ provides a sensitive measure of selective pressure acting on a protein-coding gene. Homologous genes with $\omega$ ratios of $1,<1$, or $>1$ are usually assumed to be evolving under neutral evolution, purifying selection, or positive selection, respectively. To test for deviations in the substitution rates of MoWRKY genes, we calculated $\omega$ values across all pairwise comparisons within the $54 W R K Y$ genes using the YN00 program in the PAML software package. The frequency distribution of $\omega$ values is shown in Fig. $5 \mathrm{~A}$. The results suggested that the $W R K Y$ gene family evolved mainly under strong purifying selection. However, there are several $\omega$ values greater than 1 , such as those for the comparison between MoWRKY8 and MoWRKY9 and that between MoWRKY8 and MoWRKY10, indicating that positive selection acted on these genes. Only $0.5 \%$ of the $\omega$ values approximated to 1 , indicating that no selective pressure acted on these genes.

To test whether the rate of evolution among the subgroups of $W R K Y$ genes was identical, we calculated $\omega$ values across all pairwise comparisons within each of the subgroups; the results are shown in Fig. 5 B. The average $\omega$ values of each subgroup were different. In order (highest first) they were: IIc, III, I, IIe, IId, IIb and IIa, indicating that different subgroups had evolved at different rates and that IIc had evolved the fastest.

Expression patterns of WRKY genes in drumstick under normal growth conditions and abiotic stress conditions

To investigate the responses of MoWRKY genes to stresses, we examined the expression patterns of all 54 full- 
244 length MoWRKYs under normal growth conditions and under five abiotic stresses (heat, cold, drought, salt and

245 oxidative) in different tissues (leaves, roots, stems, stem apex) using RT-PCR. As shown in Fig. 2 B, among the 54

246 MoWRKY genes, 13 genes were expressed in all tissues under all growth conditions. In contrast, six genes, including

247 MoWRKY24, the only gene with a variant WRKY domain (WRKYGKK), were not expressed in any tissue or in

248 response to any of the treatments applied in this study. Thus, these $6 W R K Y$ genes are expressed at undetectably low

249 levels, or they are only induced in response to treatments and/or in tissues not examined in our study, or they are

pseudogenes. The other $35 \mathrm{WRKY}$ genes were expressed selectively in a specific tissue and/or in response to a

specific treatment. Six of these genes were not expressed in any tissue under normal growth conditions but were

expressed under stress conditions, suggesting that they play specific roles during stress conditions. At the same time,

some genes, such as MoWRKY46, were only expressed in specific tissues under normal growth conditions but were

expressed in all tissues under certain stress conditions, indicating that these genes may also play specific roles under

stress conditions.

Nine MoWRKY genes from different subgroups were selected and their expression profiles were analyzed in root

tissue under normal growth conditions and five abiotic stresses using qRT-PCR. As shown in Fig. 6, these selected

MoWRKY genes were sensitive to abiotic stresses. All 9 exhibited a high level of transcript accumulation under cold

stress, especially MoWRKY30 (GO: 0006950), followed by MoWRKY54 (GO: 0006950 and GO: 0080134).

Interestingly, the genes that were most strongly up-regulated under cold treatment were always up-regulated in

response to heat and salt treatments. In drought stress, MoWRKY22, which had the most introns and MoWRKY3, 
265

266

267

268

269

270

271

272

273

274

275

276

277

278

279

280

281

282

283

284

285 structures and the same motifs. But the expression levels of the three genes under abiotic stresses were slightly

different. They were evidently upregulated in cold and salt to different degrees; MoWRKY53 (GO: 0006950 and GO:

0080134) and MoWRKY54 (GO: 0006950 and GO: 0080134) were also responsive to heat. Overall, the expression

patterns of MoWRKYs under various conditions suggest that different MoWRKY genes may be involved in different signaling and stress responses, and that an individual MoWRKY gene can also participate in multiple signaling and

stress process.

\section{Discussion}

WRKY transcription factors were first identified over 20 years ago (Ishiguro and Nakamura, 1994) and it has been suggested that they play important roles in stress responses and at many stages of plant growth and development (Phukan et al., 2016; Tripathi et al., 2014). Genes encoding WRKY proteins belong to a large family, with 72 members in Arabidopsis thaliana (Wang et al., 2011), 100 in Oryza sativa (Ross et al., 2007) and 104 members in the Populus trichocarpa genome (He et al., 2012). A previous study showed that Populus trichocarpa (He et al., 2012) and Daucus carota (Li et al., 2016) WRKYs could be divided into three groups. In the present study, when a phylogenetic tree of WRKYs from drumstick and Arabidopsis was constructed, we found that the 54 WRKYs from drumstick fell into three distinct groups. This result was consistent with the WRKY domain and zinc finger type classification of these WRKYs. When the subgroups of WRKY genes were compared among Arabidopsis, rice and poplar, we found that the number of each subgroup in group II was similar indicating that all members of these subgroups have probably been identified. However, the number of MoWRKYs in group III is less than the numbers in Arabidopsis and rice which are older species, implying that WRKY genes of this group in drumstick either had been lost during the course of evolution or were underrepresented in our analysis.

The WRKY conserved domain is the most important functional and evolutionary unit of WRKY transcription

Peer) reviewing PDF | (2018:09:31687:2:1:NEW 26 Apr 2019) 
286

287

288

289

290

291

292

293

294

295

296

297

298

299

300

301

302

303

304

305

306

factors. Although the WRKYGQK amino acid residues in the WRKY domain are highly conserved, there are

variants. Six sequence variations (WRKYGHK, WRKYGQN, WRKYGKK, WRKCGQK, WRKYGQT,

WRKYGMK) were found in CaWRKY genes. Six heptapeptide variants, namely WRKYGKK, WRKYGEK,

WRKYGKR, WRKYEDK, WKKYGQK, WHQYGLK, were found in soybean (Song et al., 2016). In our study,

only one variant (WRKYGKK) was found, and only in MoWRKY24 which belongs to subgroup IIc. WRKYGKK is

the most common variant in many species. In the tobacco WRKY protein family, the WRKYGKK domain could

bind specifically to a WK-box, which was significantly different from the W-box (Verk et al., 2008). In our study,

we could not detect the expression of MoWRKY24 in any tissues or under any stress conditions. The reason may be

that the expression level of MoWRKY24 was too low to be detected, or that this gene is only expressed under special

conditions, or that it has become a pseudogene. This apparent lack of expression needs to be investigated further.

The structures of the MoWRKY genes showed group-specific exon-intron patterns, as is also the case in carrot (Li

et al., 2016) and cassava (Wei et al., 2016). Exon-intron structural diversity plays an important part in the evolution

of gene families (Wei et al., 2016). The number of introns in MoWRKY genes varied from 1 to 10. However, in poplar (He et al., 2012) and cassava (Wei et al., 2016), the number of introns varied from, respectively, 0 to 6 and 1

to 5. The results indicated that MoWRKYs have more gene structure diversity than the poplar and cassava WRKY

genes. In our study, the length of the MoWRKY3 gene in group I was greater than those of any other genes. While

neither the number nor the length of exons in this gene was unusually high, there were more introns. Combined

motif compositions, we can find the variety and average length of motifs identified in MoWRKY3 were not

especially large, indicating that their functions were probably not influenced by the presence of the numerous introns.

According to a previous report, the rate of intron loss is faster than the rate of intron gain after segmental duplication

(Nuruzzaman et al., 2010) and intron loss can result from intron turnover or reverse transcription of the mature

PeerJ reviewing PDF | (2018:09:31687:2:1:NEW 26 Apr 2019) 
307

308

309

310

311

312

313

314

315

316

317

318

319

320

321

322

323

324

325

326

327

mRNA followed by homologous recombination with intron-containing alleles (He et al., 2012). In drumstick,

members of group III all contained two introns; the average number of introns in the other groups was more than

that in this group. Consequently, it can be inferred that group III developed later than other groups. The structure

and motif compositions of group III members were very similar, indicating that these genes expanded not by

merging, transfer or loss but in other ways.

WRKY proteins usually functioned as transcriptional regulators by binding to W-box to regulate defense-related

genes. In our study, we found that nearly half MoWRKY genes also contained W-box element in their promoter

regions. The same findings were identified in carrot (Li et al., 2016) and soybean (Song et al., 2016), suggesting that

these MoWRKY genes are auto-regulated by themselves or cross-regulated. Accumulating evidence suggests that

WRKY transcription factors are involved in many plant processes including development and responses to biotic

and abiotic stresses and that may due to the upstream genes specificity bind the corresponding cis element to

regulate the expression of $W R K Y$ genes. In carrot, fourteen selected $D c W R K Y$ genes responded to whitefly and aphid

infections and twelve DcWRKY genes were upregulated or downregulated under heat and/or cold treatments (Li et

al., 2016). At least 31 PeWRKY genes in moso bamboo (Li et al., 2017) and 21 CaWRKY genes in pepper (Diao et

al., 2016) were differentially expressed under abiotic stresses. Similarly, 55 VvWRKY genes in grape (Zhang and

Feng, 2014) differentially responded to at least one abiotic stress treatment. In our study, the results of expression

pattern analysis demonstrated that most MoWRKY genes had different expression levels when the seedlings were

exposed to different stresses despite highly homologous amino acid sequences and conserved domain structures.

WRKY genes within the same group may act as redundant and substitute members in regulating functions. The very

large expression differences suggested that the products of these genes have different physiological functions,

facilitating adaptation to complex challenges. Further structural analyses and investigations into the expression

Peer) reviewing PDF | (2018:09:31687:2:1:NEW 26 Apr 2019) 
328

329

330

331

332

333

334

335

336

337

338

339

340

341

342

343

344

345

346

347

patterns of the MoWRKY gene family would facilitate a more comprehensive understanding of the specific functions

of individual WRKY genes. The current investigation highlights a number of MoWRKY genes that may be involved in stress defenses, and lays a solid foundation for the selection of candidate genes for further studies.

\section{Conclusion}

The publication of drumstick genome sequences provides an opportunity for genome wide identification and characterization of WRKY TFs. Bioinformatics tools have been made in the present study to identify the putative members of WRKY genes of drumstick and subject it to characterization for gene structures, motif analysis, conserved motifs and phylogenetic tree construction. The multiple members of WRKY genes in plants reflect the redundancy and differentiated functions of these proteins which need to be explored by expression profiling. The expression profiling under different abiotic stress conditions revealed several potential MoWRKYs showing higher expression level under drought, salt, cold and heat stresses.

\section{Acknowledgements}

Authors would like to thank professor Jun Sheng and Yang Tian in Yunnan Agricultural University for their kind sharing drumstick genome sequences data. And authors also thank to the reviewers for their careful reviewing and helpful comments on the manuscript.

\section{References}

Anwar F, Latif S, Ashraf M, Gilani AH. 2007. Moringa oleifera: A food plant with multiple medicinal uses. Phytother Res 21:17-25.

Ayadi M, Hanana M, Kharrat N, Merchaoui H, Ben Marzoug R, Lauvergeat V, Rebai A, Mzid R. 2016. The WRKY transcription factor family in Citrus: valuable and useful candidate genes for Citrus breeding. Appl Biochem Biotech 
349

350

351

352

353

354

355

356

357

358

359

360

361

362

363

364

365

366

367

368

369

180:516-543.

Chen LG, Song Y, Li SJ, Zhang LP, Zou CS, Yu DQ. 2012. The role of WRKY transcription factors in plant abiotic stresses. Biochim Biophys Acta 1819:120-128.

Deng LT, Wu YL, Li JC, Ouyang KX, Ding MM, Zhang JJ, Li SQ, Lin MF, Chen HB, Hu XS. 2016. Screening reliable reference genes for RT-qPCR analysis of gene expression in Moringa oleifera. Plos One. DOI: 10.1371/journal.pone.0159458.

Diao WP, Snyder JC, Wang SB, Liu JB, Pan BG, Guo GJ. 2016. Genome-Wide identification and expression analysis of WRKY gene family in Capsicum annuum L.. Front Plant Sci. DOI: 10.3389/fpls.2016.01727.

Dou LL, Guo YN, Evans O, Pang CY, Wei HL, Song MZ, Fan SL, Yu SX. 2016. Identification and expression analysis of group III WRKY transcription factors in cotton. J Integr Agric 15:2469-2480.

Eulgem T, Rushton PJ, Robatzek S, Somssich IE. 2000. The WRKY superfamily of plant transcription factors. Trends Plant Sci 5:199-206.

Goel R, Pandey A, Trivedi PK, Asif MH. 2016. Genome-Wide analysis of the Musa WRKY gene family: evolution and differential expression during development and stress. Front Plant Sci. DOI: 10.3359/fpls.2016.00299.

Grunewald W, De Smet I, De Rybel B, Robert HS, Van De Cotte B, Willemsen V, Gheysen G, Weijers D, Friml J, Beeckman T. 2013. Tightly controlled WRKY23 expression mediates Arabidopsis embryo development. Embo Rep 14:1136-1142.

Grunewald W, Karimi M, Wieczorek K, Van de Cappelle E, Wischnitzki E, Grundler F, Inze D, Beeckman T, Gheysen G. 2008. A role for AtWRKY23 in feeding site establishment of plant-parasitic nematodes. Plant Physiol 148:358-368.

He HS, Dong Q, Shao YH, Jiang HY, Zhu SW, Cheng BJ, Xiang Y. 2012. Genome-wide survey and 
370

371

372

373

374

375

376

377

378

379

380

381

382

383

384

385

386

387

characterization of the WRKY gene family in Populus trichocarpa. Plant Cell Rep 31:1199-1217.

Huang XS, Li KQ, Xu XY, Yao ZH, Jin C, Zhang SL. 2015. Genome-wide analysis of WRKY transcription factors in white pear (Pyrus bretschneideri) reveals evolution and patterns under drought stress. BMC Genomics. DOI: 10.1186/s12864-015-2233-6.

Huang Y, Li MY, Wu P, Xu ZS, Que F, Wang F, Xiong AS. 2016. Members of WRKY Group III transcription factors are important in TYLCV defense signaling pathway in tomato (Solanum lycopersicum). BMC Genomics. DOI: $10.1186 / \mathrm{s} 12864-016-3123-2$.

Kalde M, Barth M, Somssich IE, Lippok B. 2003. Members of the Arabidopsis WRKY group III transcription factors are part of different plant defense signaling pathways. Mol Plant-Microbe Interact 16:295-305.

Lescot M, Déhais P, Thijs G, Marchal K, Moreau Y, Van de Peer Y, Rouze P, Rombauts S. 2002. PlantCARE: a database of plant cis-acting regulatory elements and a portal to tools for in silico analysis of promoter sequences.

Nucleic Acids Res 30:325-327.

Li L, Mu SH, Cheng ZC, Cheng YW, Zhang Y, Miao Y, Hou CL, Li XP, Gao J. 2017. Characterization and expression analysis of the WRKY gene family in moso bamboo. Sci Rep. DOI: 10.1038/s41598-017-06701-2.

Li MY, Xu ZS, Tian C, Huang Y, Wang F, Xiong AS. 2016. Genomic identification of WRKY transcription factors in carrot (Daucus carota) and analysis of evolution and homologous groups for plants. Sci Rep. DOI: 10.1038/srep23101.

Nuruzzaman M, Manimekalai R, Sharoni AM, Satoh K, Kondoh H, Ooka H, Kikuchi S. 2010. Genome-wide analysis of NAC transcription factor family in rice. Gene 465:30-44.

Pandey SP, Somssich IE. 2009. The role of WRKY transcription factors in plant immunity. Plant physiol 150:16481655. 
391

392

393

394

395

396

397

398

399

400

401

402

403

404

405

406

407

408

409

410

411

Phukan UJ, Jeena GS, Shukla RK. 2016. WRKY transcription factors: molecular regulation and stress responses in

plants. Front Plant Sci. DOI: 10.3389/fpls.2016.00760.

Popoola JO, Obembe OO. 2013. Local knowledge, use pattern and geographical distribution of Moringa oleifera

Lam. (Moringaceae) in Nigeria. J Ethnopharmacol 150:682-691.

Ramachandran C, Peter KV, Gopalakrishnan PK. 1980. Drumstick (Moringa oleifera): A multipurpose Indian vegetable. Econ Bot 34:276-283.

Ross CA, Liu Y, Shen QJ. 2007. The WRKY gene family in Rice (Oryza sativa). J Integr Plant Biol 49:827-842.

Shih MC, Chang CM, Kang SM, Tsai ML. 2011. Effect of different parts (leaf, stem and stalk) and seasons (summer and winter) on the chemical compositions and antioxidant activity of Moringa oleifera. Int J Mol Sci 12:6077-6088.

Singh AK, Kumar SR, Dwivedi V, Rai A, Pal S, Shasany AK, Nagegowda DA. 2017. A WRKY transcription factor from Withania somnifera regulates triterpenoid withanolide accumulation and biotic stress tolerance through modulation of phytosterol and defense pathways. New Phytol 215:1115-1131.

Smith NC, Matthews JM. 2016. Mechanisms of DNA-binding specificity and functional gene regulation by transcription factors. Curr Opin Struct Biol 38:68-74.

Song H, Wang PF, Hou L, Zhao SZ, Zhao CZ, Xia H, Li PC, Zhang Y, Bian XT, Wang XJ. 2016. Global analysis of WRKY genes and their response to dehydration and salt stress in Soybean. Front Plant Sci. DOI: 10.3389/fpls.2016.00009.

Tian Y, Zeng Y, Zhang J, Yang CG, Yan L, Wang XJ, Shi CY, Xie J, Dai TY, Peng L, Zeng HY, Xu AN, Huang YW, Zhang JJ, Ma X, Dong Y, Hao SM, Sheng J. 2015. High quality reference genome of drumstick tree (Moringa oleifera Lam.), a potential perennial crop. Sci China 58:627-638.

Tripathi P, Rabara RC, Rushton PJ. 2014. A systems biology perspective on the role of WRKY transcription factors 
412 in drought responses in plants. Planta 239:255-266.

413 Ulker B, Somssich IE. 2004. WRKY transcription factors: from DNA binding towards biological function. Curr

414 Opin Plant Biol 7:491-498.

415 Verk MCV, Pappaioannou D, Neeleman L, Bol JF, Linthorst HJM. 2008. A novel WRKY transcription factor is

416 required for induction of PR-1a gene expression by salicylic acid and bacterial elicitors. Plant Physiol 146:1983-

4171995.

418 Wang JJ, Tao F, Tian W, Guo ZF, Chen XM, Xu XM, Shang HS, Hu XP. 2017. The wheat WRKY transcription

factors TaWRKY49 and TaWRKY62 confer differential high-temperature seedling-plant resistance to Puccinia

striiformis f. sp. tritici. Plos One. DOI: 10.1371/journal.pone.0181963.

Wang QS, Wang MH, Zhang XZ, Hao BJ, Kaushik SK, Pan YC. 2011. WRKY gene family evolution in

Arabidopsis thaliana. Genet 139:973-983.

Wei YX, Shi HT, Xia ZQ, Tie WW, Ding ZH, Yan Y, Wang WQ, Hu W, Li KM. 2016. Genome-wide identification

and expression analysis of the WRKY gene family in Cassava. Fron Plant Sci. DOI: 10.3389/fpls.2016.00025.

Wu M, Liu HL, Han GM, Cai RH, Pan F, Xiang Y. 2017. A moso bamboo WRKY gene PeWRKY83 confers

salinity tolerance in transgenic Arabidopsis plants. Sci Rep. DOI: 10.1038/s41598-07-10795-z.

Xiang JS, Tang S, Zhi H, Jia GQ, Wang HJ, Diao XM. 2017. Loose paniclel encoding a novel WRKY transcription

Plos One. DOI: 10.1371/journal.pone.0178730.

Yang L, Zhao X, Yang F, Fan D, Jiang YZ, Luo KM. 2016. PtrWRKY19, a novel WRKY transcription factor, 
433

434

435

436

437

438

439

440

441

442

443

444

445

446

447

448

449

450

451

452

453

Yang ZH. 2007. PAML 4: phylogenetic analysis by maximum likelihood. Mol Biol Evol 24: 1586-1591.

Ye YJ, Xiao YY, Han YC, Shan W, Fan ZQ, Xu QG, Kuang JF, Lu WJ, Lakshmanan P, Chen JY. 2016. Banana

fruit VQ motif-containing protein5 represses cold-responsive transcription factor MaWRKY26 involved in the

regulation of JA biosynthetic genes. Sci Rep. DOI: 10.1038/srep23632.

Yokotani N, Sato Y, Tanabe S, Chujo T, Shimizu T, Okada K, Yamane H, Shimono M, Sugano S, Takatsuji H,

Kaku H, Minami E, Nishizawa Y. 2013. WRKY76 is a rice transcriptional repressor playing opposite roles in blast

disease resistance and cold stress tolerance. J Exp Bot 64:5085-5097.

Zhang LP, Chen LG, Yu DQ. 2018. Transcription Factor WRKY75 Interacts with DELLA Proteins to Affect

Flowering. Plant Physiol 176, 790-803.

Zhang JJ, Yang YS, Lin MF, Li SQ, Tang Y, Chen HB, Chen XY. 2017. An efficient micropropagation protocol for direct organogenesis from leaf explants of an economically valuable plant, drumstick (Moringa oleifera Lam.). Ind Crops Prod 103:59-63.

Zhang Y, Feng JC. 2014. Identification and Characterization of the Grape WRKY Family. Biomed Res Int. DOI:

$10.1155 / 2014 / 787680$.

Zhang YJ, Wang LJ. 2005. The WRKY transcription factor superfamily: its origin in eukaryotes and expansion in plants. BMC Evol Biol. DOI: 10.1186/1471-2148-5-1.

\section{Caption}

Fig. 1 Phylogenetic tree of the WRKY conserved domain from drumstick and selected Arabidopsis. The 
454

455

456

457

458

459

460

461

462

463

464

465

466

467

bootstrap test was performed with 1000 replicates.

Fig. 2 Exon-intron composition and expression patterns of $M o W R K Y$ genes. (A) Exon-intron composition. (B)

Expression patterns.

Fig. 3 Distribution of conserved motifs in MoWRKYs. Different colors represent different motifs.

Fig. 4 Phylogenetic tree of 81 group III WRKY proteins from drumstick and other seven species. O. sativa (blue triangles and lines), $P$. euphratica (green lines), $V$. vinifera (orange lines), $P$. patens (purple triangle), $A$. thaliana (brown triangle and lines), S. moellendorfii (grass green lines) and P. abies (red lines).

Fig. 5 Frequency distribution and average values of Ka/Ks ratios. (A) Frequency distribution between any two drumstick WRKY genes. (B) Average values of Ka/Ks across sub-groups of drumstick WRKYs.

Fig. 6 Expression profiles for 9 selected MoWRKY genes in root under different stresses. (A) I-MoWRKY3; (B) IIa-MoWRKY22; (C) IIb-MoWRKY30; (D) IIe-MoWRKY50; (E) IId-MoWRKY27; (F) IIe-MoWRKY35; (G) IIIMoWRKY49; (H) III-MoWKRY53; (I) III-MoWKRY54.

Fig. S1 Phylogenetic tree of MoWRKYs. 
Figure 1

Phylogenetic tree of the WRKY conserved domain from drumstick and selected Arabidopsis.

The bootstrap test was performed with 1000 replicates.

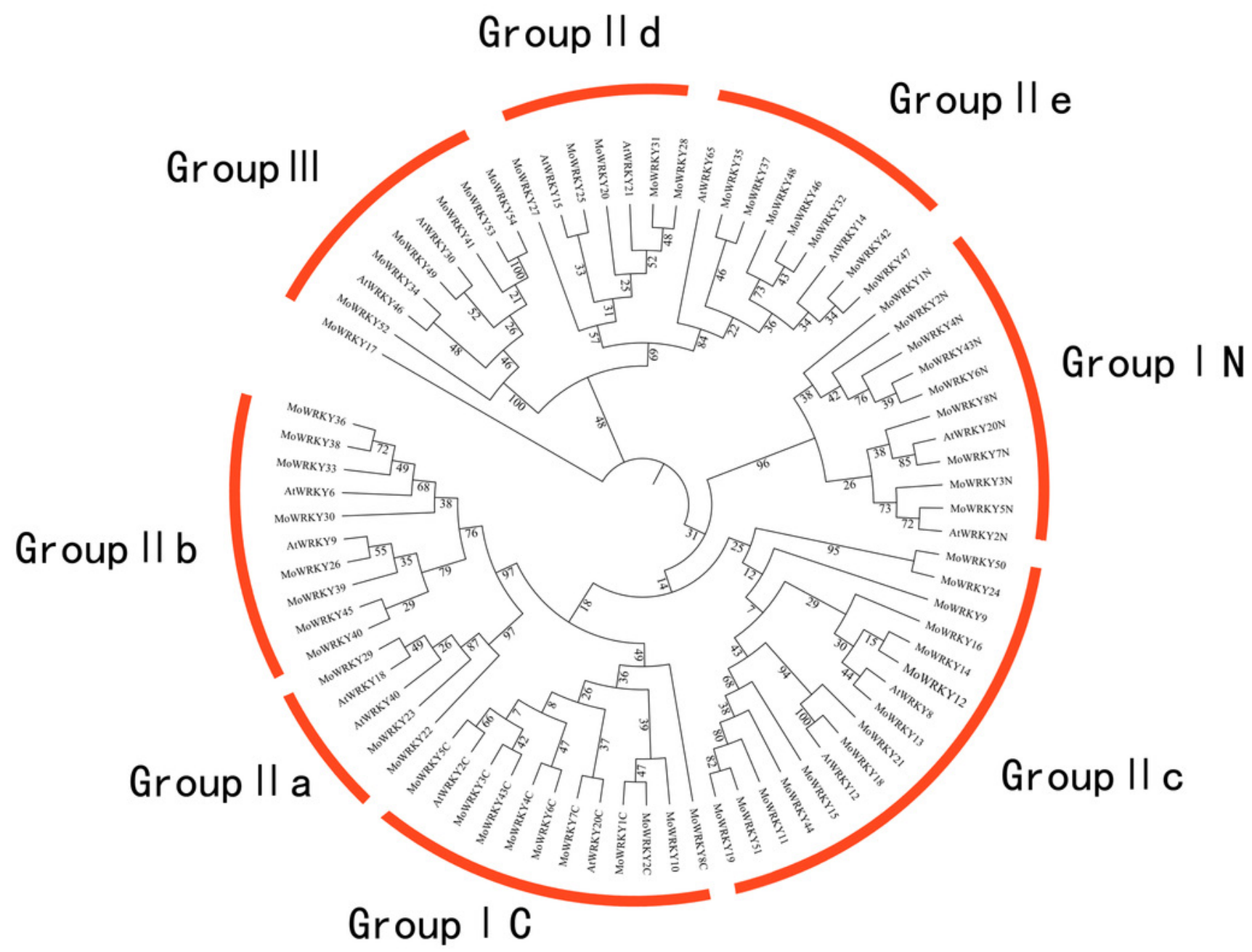


Figure 2

Exon-intron composition and expression patterns of MoWRKY genes.

(A) Exon-intron composition. (B) Expression patterns.

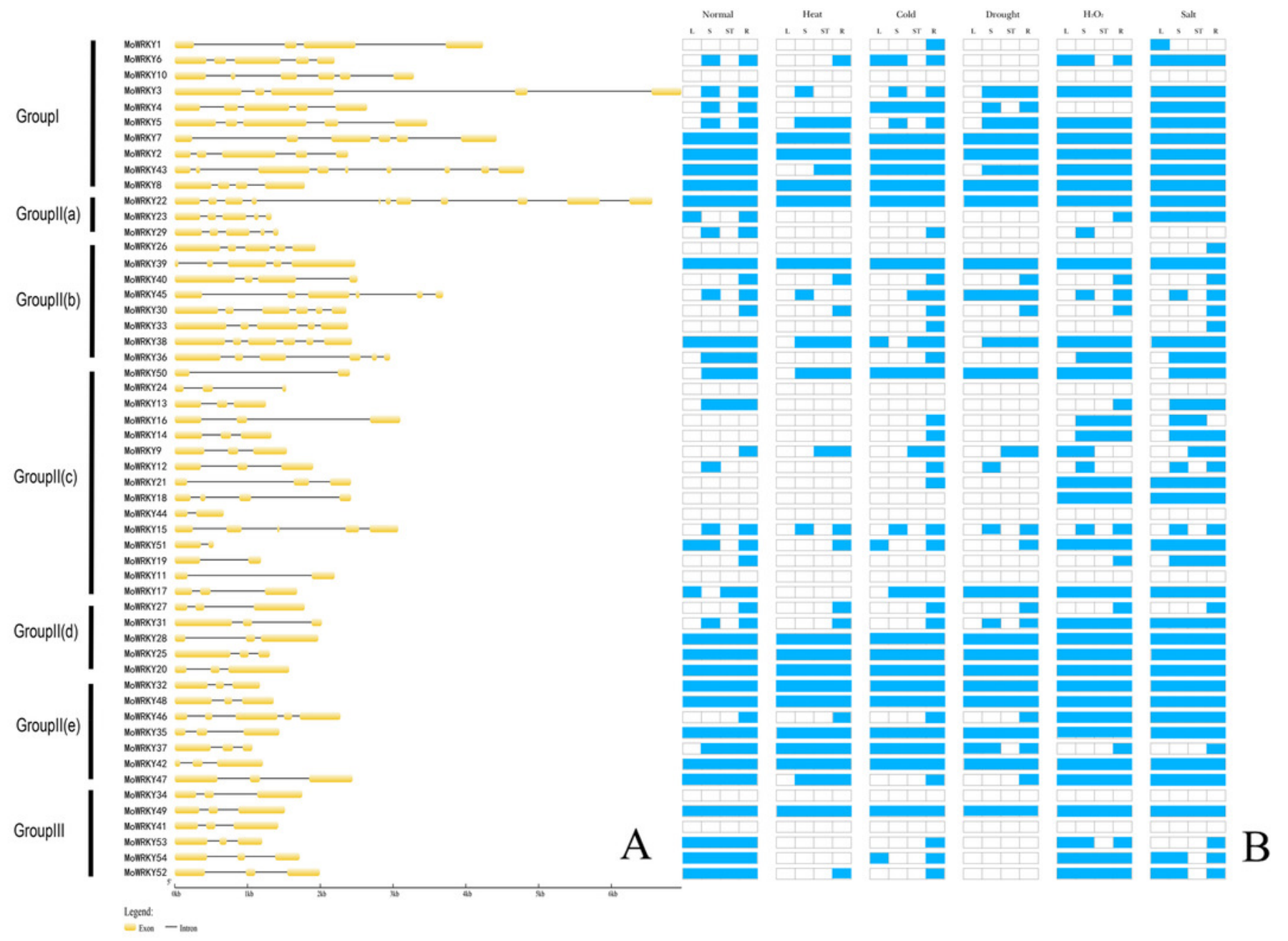


Figure 3

Distribution of conserved motifs in MoWRKYs.

Different colors represent different motifs.

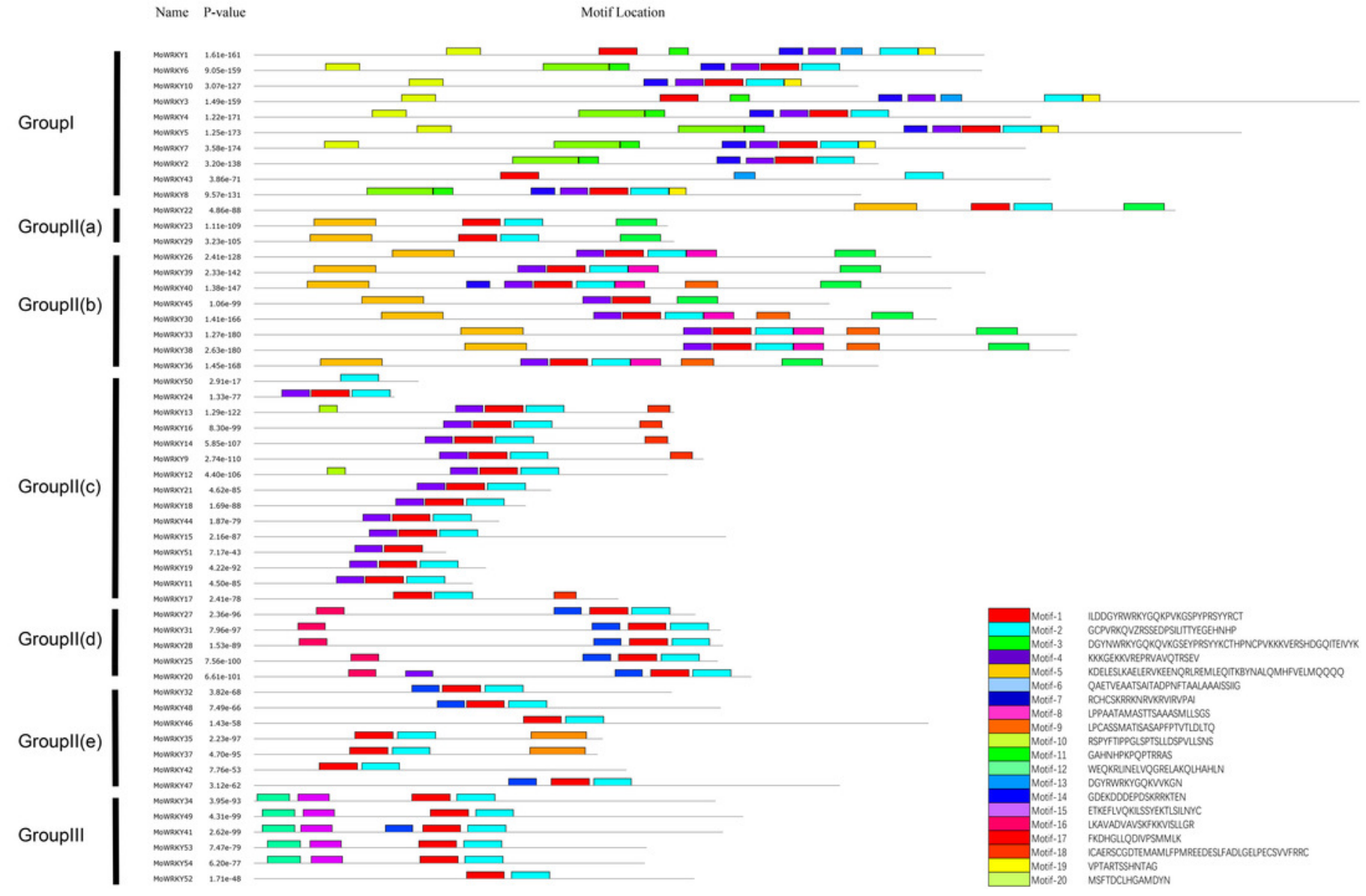


Figure 4

Phylogenetic tree of 81 group III WRKY proteins from drumstick and other seven species.

$O$. sativa (blue triangles and lines), $P$. euphratica (green lines), $V$. vinifera (orange lines), $P$. patens (purple triangle), A. thaliana (brown triangle and lines), S. moellendorfii (grass green lines) and $P$. abies (red lines). 


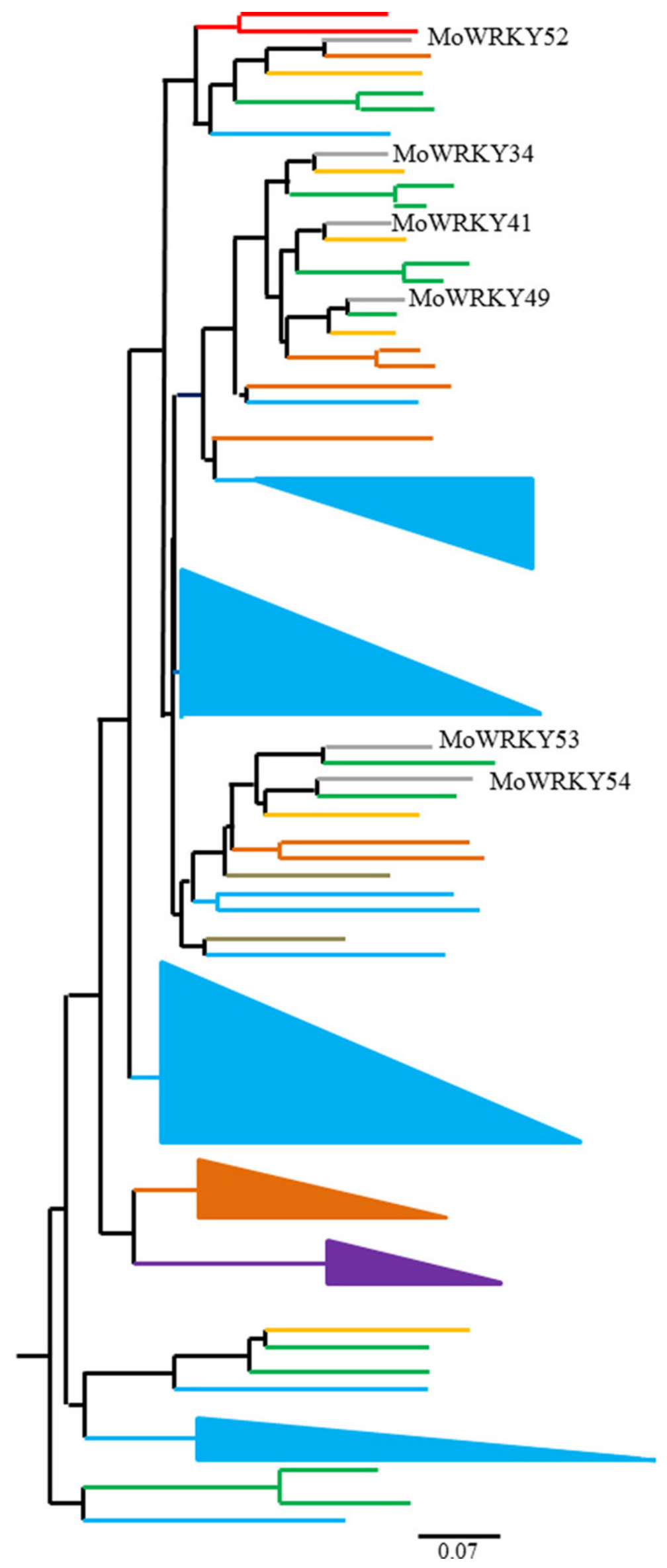

Peer) reviewing PDF | (2018:09:31687:2:1:NEW 26 Apr 2019) 
Figure 5

Frequency distribution and average values of Ka/Ks ratios.

(A) Frequency distribution between any two drumstick WRKY genes. (B) Average values of $\mathrm{Ka} / \mathrm{Ks}$ across sub-groups of drumstick WRKYs.
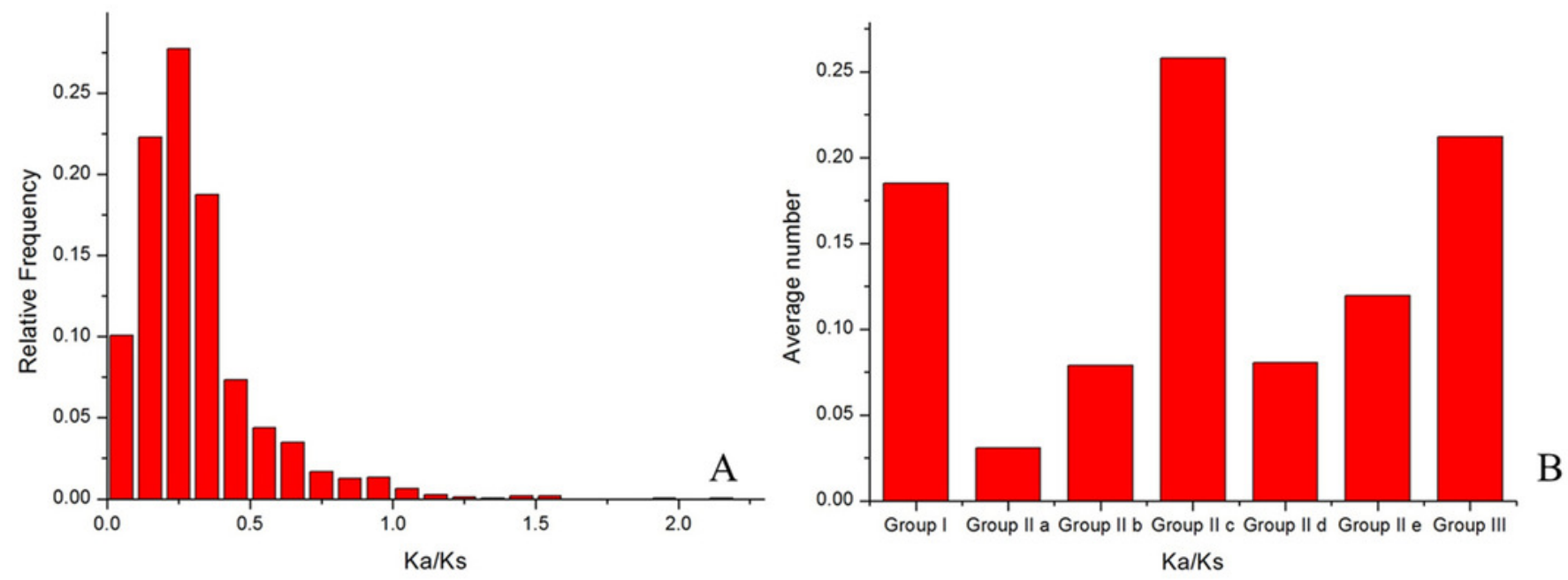
Figure 6

Expression profiles for 9 selected MoWRKY genes in root under different stresses.
(A) I-MoWRKY3;
(B) Ila-MoWRKY22;
(C) IIb-MoWRKY3O;
(D) Ile-MOWRKY50;
(E) Ild-MoWRKY27;

(F) IIe-MoWRKY35; (G) III-MoWRKY49; (H) III-MoWKRY53; (I) III-MoWKRY54.

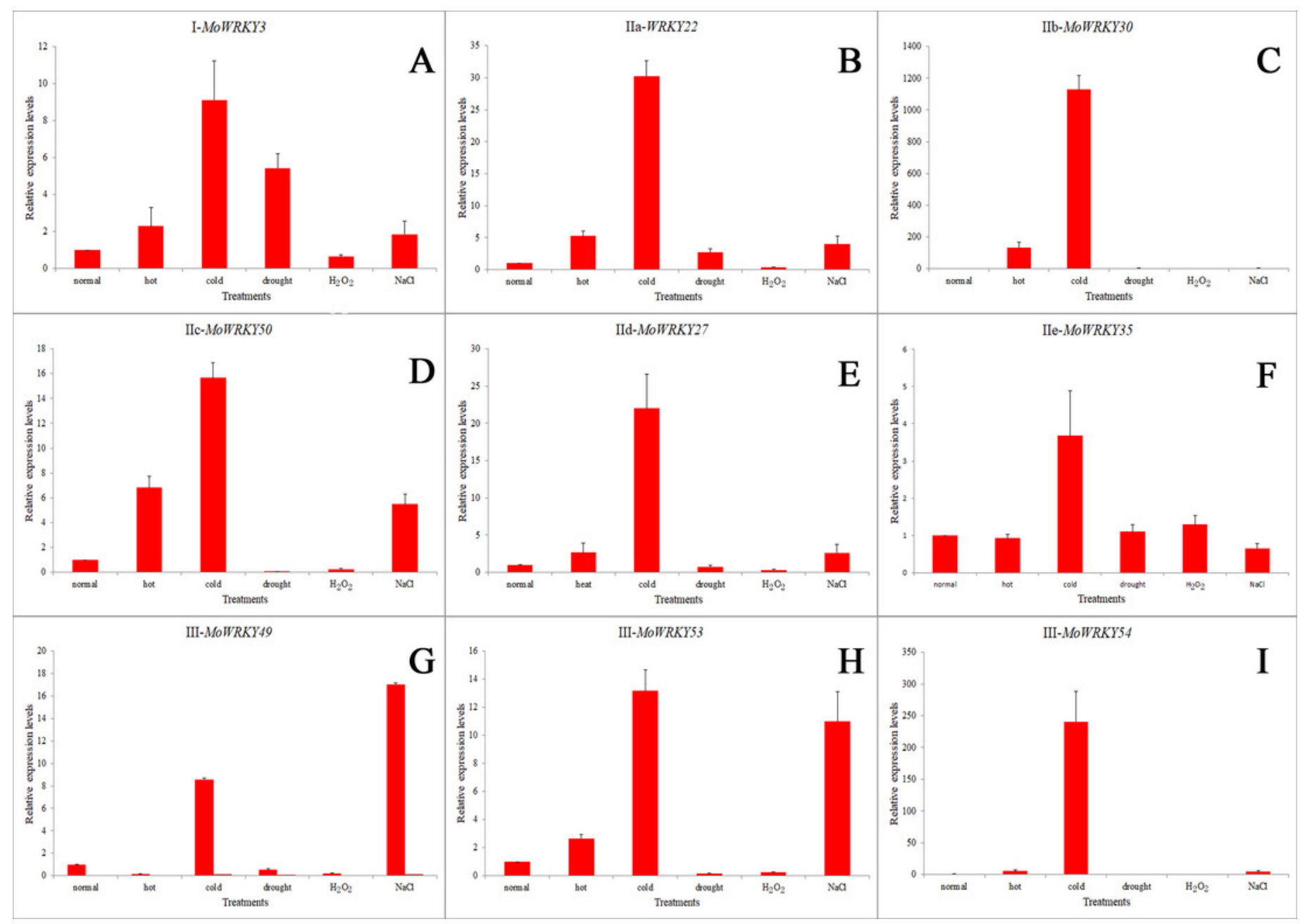


Table $\mathbf{1}$ (on next page)

Full-length WRKY genes identified from drumstick genome 
Table 1 Full-length WRKY genes identified from drumstick genome

\begin{tabular}{|c|c|c|c|c|}
\hline Class & Gene name & Annotation ID & Conserved motify & Zinc finger \\
\hline I & MoWRKY43 & lamu_GLEAN_10016673 & WRKYGQK & $\mathrm{C}-\mathrm{X}_{4}-\mathrm{C}-\mathrm{X}_{23}-\mathrm{HXH}$ \\
\hline I & MoWRKY8 & lamu_GLEAN_10019070 & WRKYGQK & $\mathrm{C}-\mathrm{X}_{5}-\mathrm{C}-\mathrm{X}_{23}-\mathrm{HXH}$ \\
\hline I & MoWRKY2 & lamu_GLEAN_10014815 & WRKYGQK & $\mathrm{C}-\mathrm{X}_{5}-\mathrm{C}-\mathrm{X}_{23}-\mathrm{HXH}$ \\
\hline I & MoWRKY3 & lamu_GLEAN_10006432 & WRKYGQK & $\mathrm{C}-\mathrm{X}_{4}-\mathrm{C}-\mathrm{X}_{23}-\mathrm{HXH}$ \\
\hline I & MoWRKY6 & lamu_GLEAN_10006277 & WRKYGQK & $\mathrm{C}-\mathrm{X}_{5}-\mathrm{C}-\mathrm{X}_{23}-\mathrm{HXH}$ \\
\hline I & MoWRKY4 & lamu_GLEAN_10010412 & WRKYGQK & $\mathrm{C}-\mathrm{X}_{5}-\mathrm{C}-\mathrm{X}_{23}-\mathrm{HXH}$ \\
\hline $\mathrm{I}$ & MoWRKY7 & lamu_GLEAN_10010176 & WRKYGQK & $\mathrm{C}-\mathrm{X}_{5}-\mathrm{C}-\mathrm{X}_{23}-\mathrm{HXH}$ \\
\hline I & MoWRKY5 & lamu_GLEAN_10005513 & WRKYGQK & $\mathrm{C}-\mathrm{X}_{5}-\mathrm{C}-\mathrm{X}_{23}-\mathrm{HXH}$ \\
\hline I & MoWRKY1 & lamu_GLEAN_10000767 & WRKYGQK & $\mathrm{C}-\mathrm{X}_{5}-\mathrm{C}-\mathrm{X}_{23}-\mathrm{HXH}$ \\
\hline I & MoWRKY10 & lamu_GLEAN_10018171 & WRKYGQK & $\mathrm{C}-\mathrm{X}_{5}-\mathrm{C}-\mathrm{X}_{23}-\mathrm{HXH}$ \\
\hline IIa & MoWRKY22 & lamu_GLEAN_10016899 & WRKYGQK & $\mathrm{C}-\mathrm{X}_{5}-\mathrm{C}-\mathrm{X}_{23}-\mathrm{HXH}$ \\
\hline IIa & MoWRKY23 & lamu_GLEAN_10005532 & WRKYGQK & $\mathrm{C}-\mathrm{X}_{5}-\mathrm{C}-\mathrm{X}_{23}-\mathrm{HXH}$ \\
\hline IIa & MoWRKY29 & lamu_GLEAN_10016902 & WRKYGQK & $\mathrm{C}-\mathrm{X}_{5}-\mathrm{C}-\mathrm{X}_{23}-\mathrm{HXH}$ \\
\hline IIb & MoWRKY26 & lamu_GLEAN_10015703 & WRKYGQK & $\mathrm{C}-\mathrm{X}_{5}-\mathrm{C}-\mathrm{X}_{23}-\mathrm{HXH}$ \\
\hline IIb & MoWRKY36 & lamu_GLEAN_10013925 & WRKYGQK & $\mathrm{C}-\mathrm{X}_{5}-\mathrm{C}-\mathrm{X}_{23}-\mathrm{HXH}$ \\
\hline $\mathrm{IIb}$ & MoWRKY30 & lamu_GLEAN_10010114 & WRKYGQK & $\mathrm{C}-\mathrm{X}_{5}-\mathrm{C}-\mathrm{X}_{23}-\mathrm{HXH}$ \\
\hline IIb & MoWRKY33 & lamu_GLEAN_10005737 & WRKYGQK & $\mathrm{C}-\mathrm{X}_{5}-\mathrm{C}-\mathrm{X}_{23}-\mathrm{HXH}$ \\
\hline $\mathrm{IIb}$ & MoWRKY38 & lamu_GLEAN_10016471 & WRKYGQK & $\mathrm{C}-\mathrm{X}_{5}-\mathrm{C}-\mathrm{X}_{23}-\mathrm{HXH}$ \\
\hline $\mathrm{IIb}$ & MoWRKY40 & lamu_GLEAN_10015347 & WRKYGQK & $\mathrm{C}-\mathrm{X}_{5}-\mathrm{C}-\mathrm{X}_{23}-\mathrm{HXH}$ \\
\hline IIb & MoWRKY39 & lamu_GLEAN_10018130 & WRKYGQK & $\mathrm{C}-\mathrm{X}_{5}-\mathrm{C}-\mathrm{X}_{23}-\mathrm{HXH}$ \\
\hline IIb & MoWRKY45 & lamu_GLEAN_10004479 & WRKYGQK & $\mathrm{C}-\mathrm{X}_{5}-\mathrm{C}-\mathrm{X}_{23}-\mathrm{HXH}$ \\
\hline IIc & MoWRKY17 & lamu_GLEAN_10015158 & WRKYGQK & $\mathrm{C}-\mathrm{X}_{4}-\mathrm{C}-\mathrm{X}_{23}-\mathrm{HXH}$ \\
\hline IIc & MoWRKY21 & lamu_GLEAN_10005936 & WRKYGQK & $\mathrm{C}-\mathrm{X}_{4}-\mathrm{C}-\mathrm{X}_{23}-\mathrm{HXH}$ \\
\hline IIc & MoWRKY18 & lamu_GLEAN_10014440 & WRKYGQK & $\mathrm{C}-\mathrm{X}_{4}-\mathrm{C}-\mathrm{X}_{23}-\mathrm{HXH}$ \\
\hline IIc & MoWRKY16 & lamu_GLEAN_10002123 & WRKYGQK & $\mathrm{C}-\mathrm{X}_{4}-\mathrm{C}-\mathrm{X}_{23}-\mathrm{HXH}$ \\
\hline
\end{tabular}




\begin{tabular}{|c|c|c|c|c|}
\hline IIc & MoWRKY50 & lamu_GLEAN_10005926 & - & $\mathrm{C}-\mathrm{X}_{4}-\mathrm{C}-\mathrm{X}_{23}-\mathrm{HXH}$ \\
\hline IIc & MoWRKY9 & lamu_GLEAN_10018985 & WRKYGQK & $\mathrm{C}-\mathrm{X}_{4}-\mathrm{C}-\mathrm{X}_{23}-\mathrm{HXH}$ \\
\hline Class & Gene name & Annotation ID & Conserved motify & Zinc finger \\
\hline IIc & MoWRKY14 & lamu_GLEAN_10013856 & WRKYGQK & $\mathrm{C}-\mathrm{X}_{4}-\mathrm{C}-\mathrm{X}_{23}-\mathrm{HXH}$ \\
\hline IIc & MoWRKY24 & lamu_GLEAN_10017233 & WRKYGKK & $\mathrm{C}-\mathrm{X}_{4}-\mathrm{C}-\mathrm{X}_{23}-\mathrm{HXH}$ \\
\hline IIc & MoWRKY13 & lamu_GLEAN_10016027 & WRKYGQK & $\mathrm{C}-\mathrm{X}_{4}-\mathrm{C}-\mathrm{X}_{23}-\mathrm{HXH}$ \\
\hline IIc & MoWRKY12 & lamu_GLEAN_10010840 & WRKYGQK & $\mathrm{C}-\mathrm{X}_{4}-\mathrm{C}-\mathrm{X}_{23}-\mathrm{HXH}$ \\
\hline IIc & MoWRKY44 & lamu_GLEAN_10009886 & WRKYGQK & $\mathrm{C}-\mathrm{X}_{4}-\mathrm{C}-\mathrm{X}_{23}-\mathrm{HXH}$ \\
\hline IIc & MoWRKY15 & lamu_GLEAN_10014128 & WRKYGQK & $\mathrm{C}-\mathrm{X}_{4}-\mathrm{C}-\mathrm{X}_{23}-\mathrm{HXH}$ \\
\hline IIc & MoWRKY51 & lamu_GLEAN_10003738 & WRKYGQK & $\mathrm{C}-\mathrm{X}_{4}-\mathrm{C}-\mathrm{X}_{23}-\mathrm{HXH}$ \\
\hline IIc & MoWRKY11 & lamu_GLEAN_10007141 & WRKYGQK & $\mathrm{C}-\mathrm{X}_{4}-\mathrm{C}-\mathrm{X}_{23}-\mathrm{HXH}$ \\
\hline IIc & MoWRKY19 & lamu_GLEAN_10017855 & WRKYGQK & $\mathrm{C}-\mathrm{X}_{4}-\mathrm{C}-\mathrm{X}_{23}-\mathrm{HXH}$ \\
\hline IId & MoWRKY31 & lamu_GLEAN_10007564 & WRKYGQK & $\mathrm{C}-\mathrm{X}_{5}-\mathrm{C}-\mathrm{X}_{23}-\mathrm{HXH}$ \\
\hline IId & MoWRKY28 & lamu_GLEAN_10011212 & WRKYGQK & $\mathrm{C}-\mathrm{X}_{5}-\mathrm{C}-\mathrm{X}_{23}-\mathrm{HXH}$ \\
\hline IId & MoWRKY 27 & lamu_GLEAN_10016840 & WRKYGQK & $\mathrm{C}-\mathrm{X}_{5}-\mathrm{C}-\mathrm{X}_{23}-\mathrm{HXH}$ \\
\hline IId & MoWRKY25 & lamu_GLEAN_10013546 & WRKYGQK & $\mathrm{C}-\mathrm{X}_{5}-\mathrm{C}-\mathrm{X}_{23}-\mathrm{HXH}$ \\
\hline IId & MoWRKY20 & lamu_GLEAN_10005795 & WRKYGQK & $\mathrm{C}-\mathrm{X}_{5}-\mathrm{C}-\mathrm{X}_{23}-\mathrm{HXH}$ \\
\hline IIe & MoWRKY47 & lamu_GLEAN_10007164 & WRKYGQK & $\mathrm{C}-\mathrm{X}_{5}-\mathrm{C}-\mathrm{X}_{23}-\mathrm{HXH}$ \\
\hline IIe & MoWRKY35 & lamu_GLEAN_10001324 & WRKYGQK & $\mathrm{C}-\mathrm{X}_{5}-\mathrm{C}-\mathrm{X}_{23}-\mathrm{HXH}$ \\
\hline IIe & MoWRKY37 & lamu_GLEAN_10016099 & WRKYGQK & $\mathrm{C}-\mathrm{X}_{5}-\mathrm{C}-\mathrm{X}_{23}-\mathrm{HXH}$ \\
\hline IIe & MoWRKY42 & lamu_GLEAN_10013842 & WRKYGQK & $\mathrm{C}-\mathrm{X}_{5}-\mathrm{C}-\mathrm{X}_{23}-\mathrm{HXH}$ \\
\hline IIe & MoWRKY46 & lamu_GLEAN_10012212 & WRKYGQK & $\mathrm{C}-\mathrm{X}_{5}-\mathrm{C}-\mathrm{X}_{23}-\mathrm{HXH}$ \\
\hline IIe & MoWRKY32 & lamu_GLEAN_10009888 & WRKYGQK & $\mathrm{C}-\mathrm{X}_{5}-\mathrm{C}-\mathrm{X}_{23}-\mathrm{HXH}$ \\
\hline IIe & MoWRKY48 & lamu_GLEAN_10014133 & WRKYGQK & $\mathrm{C}-\mathrm{X}_{5}-\mathrm{C}-\mathrm{X}_{23}-\mathrm{HXH}$ \\
\hline III & MoWRKY52 & lamu_GLEAN_10005191 & WRKYGQK & $\mathrm{C}-\mathrm{X}_{7}-\mathrm{C}-\mathrm{X}_{23}-\mathrm{HXC}$ \\
\hline III & MoWRKY41 & lamu_GLEAN_10009829 & WRKYGQK & $\mathrm{C}-\mathrm{X}_{7}-\mathrm{C}-\mathrm{X}_{23}-\mathrm{HXC}$ \\
\hline III & MoWRKY34 & lamu_GLEAN_10014082 & WRKYGQK & $\mathrm{C}-\mathrm{X}_{7}-\mathrm{C}-\mathrm{X}_{23}-\mathrm{HXC}$ \\
\hline
\end{tabular}




$\begin{array}{lllll}\text { III } & \text { MoWRKY49 } & \text { lamu_GLEAN_10012174 } & \text { WRKYGQK } & \text { C-X }-\mathrm{C}-\mathrm{X}_{23}-\mathrm{HXC} \\ \text { III } & \text { MoWRKY54 } & \text { lamu_GLEAN_10006335 } & \text { WRKYGQK } & \text { C-X }-\mathrm{C}-\mathrm{X}_{23}-\mathrm{HXC} \\ \text { III } & \text { MoWRKY53 } & \text { lamu_GLEAN_10005192 } & \text { WRKYGQK } & \text { C-X }-\mathrm{C}-\mathrm{X}_{23}-\mathrm{HXC}\end{array}$

2

3 


\section{Table 2 (on next page)}

The predicted stress-responsive cis-acting elements in the promoters of MoWRKYS 
Table 2 The predicted stress-responsive cis-acting elements in the promoters of MoWRKYS

\begin{tabular}{|c|c|c|}
\hline $\begin{array}{l}\text { Cis-acting } \\
\text { elements }\end{array}$ & Function & Genes \\
\hline ABRE & Involved in $\mathrm{ABA}$ response & $\begin{array}{c}\text { MoWRKY1, 3, 4, 5, 6, 8, 9, 11, 13, 14, 15, 17, } \\
19,20,21,23,24,25,26,28,29,31,33,34 \\
37,38,40,42,43,44,46,47,48,49,51,52 \\
53,54\end{array}$ \\
\hline ARE & $\begin{array}{l}\text { Essential for the anaerobic } \\
\text { induction }\end{array}$ & $\begin{array}{c}\text { MoWRKY 1, 2, 4, 5, 6, 7, 8, 9, 10, 12, 15, 16, } \\
\begin{array}{c}17,18,20,21,23,24,26,27,28,30,31,32 \\
33,34,37,38,41,42,43,45,46,47,49,51 \\
52,53,54\end{array}\end{array}$ \\
\hline MBS & Involved in drought inducibility & $\begin{array}{c}\text { MoWRKY 2, 4, 6, 7, 8, 10,11, 12, 13, 14, 16, } \\
\begin{array}{c}17,19,20,21,22,23,24,25,26,27,28,29 \\
30,31,32,33,34,35,36,38,39,40,42,43 \\
44,45,47,48,49,50,53,54\end{array}\end{array}$ \\
\hline HSE & Involved in heat stress response & $\begin{array}{c}\text { MoWRKY 3, 4, 5, 9, 12, 14, 16, 19, 20, 21, 22, } \\
23,26,27,28,29,30,32,33,35,36,38,39, \\
40,41,43,45,46,47,49,50,51,53\end{array}$ \\
\hline Sp1 & Light responsive element & $\begin{array}{c}\text { MoWRKY 4, 5, 6, 9, 10, 11, 13, 14, 18, 19, 20, } \\
21,23,24,27,28,31,35,37,38,39,41,42, \\
44,46,47,48,50,52,53,54\end{array}$ \\
\hline G-box & $\begin{array}{l}\mathrm{ABA} \text {, light, } \mathrm{UV} \text { and hurt } \\
\text { responsive element }\end{array}$ & $\begin{array}{c}\text { MoWRKY 1, 2, 3, 4, 5, 6, 7, 8, 9,10,11,12, } \\
13,14,15,16,17,19,20,21,23,24,25,26 \\
28,29,31,32,33,34,35,36,37,38,39,40 \\
42,43,44,45,46,47,48,49,51,53,54\end{array}$ \\
\hline Box 4 & $\begin{array}{l}\text { Part of a conserved DNA } \\
\text { module involved in light } \\
\text { response }\end{array}$ & $\begin{array}{c}\text { MoWRKY 1, 2, 3, 4, 6, 8, 9, 10,11,12,13,14, } \\
17,18,19,20,21,22,23,25,26,27,28,29, \\
30,31,32,33,34,35,36,37,38,39,40,41, \\
42,43,44,45,46,48,49,50,51,52,53\end{array}$ \\
\hline $\begin{array}{l}\text { CGTCA } \\
\text { motif }\end{array}$ & Involved in MeJA response & $\begin{array}{c}\operatorname{MoWRKY} 1,3,4,6,7,8,9,11,12,15,16,17 \\
18,19,21,22,24,25,27,28,29,30,33,34, \\
35,37,38,39,40,41,43,44,46,48,49,50, \\
51,52,53,54\end{array}$ \\
\hline $\begin{array}{l}\text { TGACG } \\
\text { motif }\end{array}$ & Involved in MeJA response & $\begin{array}{c}\text { MoWRKY 1, 3, 4, 6, 7, 8, 11, 12, 15, 16, 17, } \\
18,19,21,22,24,25,27,28,29,30,33,34 \\
35,37,38,39,40,41,43,44,46,48,49,50 \\
51,52,53,54\end{array}$ \\
\hline GT1 motif & Light responsive element & $\begin{array}{c}\text { MoWRKY 1, 6, 7, 9, 11, 12, 13,15,16,18,19, } \\
20,22,23,24,26,27,29,34,35,36,37,39, \\
40,43,44,45,47,48,49,50,54\end{array}$ \\
\hline
\end{tabular}


